\title{
Maternal occupational exposure during pregnancy and the risk of spina bifida
}

Birgitte M Blatter, Nel Roeleveld, Gerhard A Zielhuis, Fons J M Gabreëls, André L M Verbeek

\begin{abstract}
Objectives-A case-control study was carried out to explore associations between spina bifida and occupational exposure of the mother.

Methods-The cases were children with spina bifida aperta born between 1980 and 1992 from nine hospitals in the Netherlands. The controls were children born healthy in the same period as the cases, from hospitals and from the general population. Data collection was carried out in two steps. Firstly, postal questionnaires were sent to all the parents of cases and controls to gather information on occupations and potential confounders. In the second phase of the study, information on specific exposures was collected by means of job and task specific personal interviews. Interviews were performed with 55 case mothers and 66 control mothers who had occupations with a potential for chemical or physical exposure. Those exposures were assumed to be negligible for-for example, teachers and secretaries, so personal interviews were not indicated for these women. Information was collected on specific tasks in the period just after conception, and on the associated use of chemical or physical agents, frequency of exposure, and use of protective equipment.
\end{abstract}

Results-The analyses of occupation showed an increased risk for women working in agricultural occupations (OR $=3.4$, CI:1.3-9.0), and, although less distinct, for cleaning women $(O R=1 \cdot 7$, CI:0.9-3.4). Only a few women seemed to be occupationally exposed to chemical or physical agents. No differences in occurrence of specific exposures could be detected between cases and controls. Besides, no differences were seen in pesticide or disinfectant exposure among case and control mothers in agricultural occupations.

Conclusions-Occupational exposures of the mother during pregnancy were infrequent and did not seem to play an important part in the aetiology of spina bifida in this study. The association found between spina bifida and maternal agricultural occupations could not be explained by the use of pesticides by the mother or by any other occupational exposure.

(Occup Environ Med 1996;53:80-86)
Keywords: spina bifida; occupational exposure; pregnancy

Spina bifida is a congenital malformation that is caused by a failure in the process of neural tube closure. Although its aetiology is still largely unknown, both genetic and environmental factors seem to play an equally important part in the aetiology. One factor that seems to be associated with the prevalence of spina bifida is socioeconomic status of the parents. ${ }^{13}$ Since that fact was established, research into vitamin status during pregnancy, with emphasis on folic acid, has been expanded. It has been found that a deficiency of this B vitamin is one of the causes of neural tube defects; supplementation with folic acid seems to have a preventive effect. ${ }^{4-7}$ Another possible aetiological factor that is related to socioeconomic status, is maternal occupational exposure to chemicals or radiation during the first month of pregnancy.

Just a few studies have been performed to investigate the relation between maternal occupation and spina bifida. ${ }^{8}$ Some evidence was found for an increased risk among women working in industry, construction, transport and communication, ${ }^{910}$ dental surgeries, ${ }^{11}$ nursing, ${ }^{12}$ hairdressing, ${ }^{13}$ and farming. ${ }^{13}{ }^{14}$ Occupational titles were used as a surrogate measure for exposure in these studies. This measure is too general for accurate exposure assessment: the same job title reported by different subjects may correspond to huge variations in exposure, whereas different job titles reported by different subjects may have the same or similar exposures. ${ }^{15}$ Therefore, it is important to evaluate individual job and time specific exposures. As obtaining this kind of information is costly and time consuming studies investigating the influence of occupational exposure are scarce.

A Finnish study from Holmberg and Nurminen ${ }^{16}$ showed an increased risk of central nervous system defects (including a large number of neural tube defects) for women working with organic solvents. The authors extended the data collection of this study and recently reported on the relation between birth defects and agricultural work. ${ }^{17}$ Unfortunately, the effect of pesticide exposure could not be studied as only one central nervous system case mother and one control mother had been moderately or heavily exposed to pesticides. In a study on parental occupation and anencephalic births in the United States ${ }^{18}$ the authors investigated in particular whether pesticide and solvent exposure were of 
importance. However, the number of exposed case and control mothers in this study again was too small to find any exposure effect.

The present paper describes a multicentre case-control study including a relatively large number of spina bifida cases, in which the relation between occupational exposures of the mother and the risk of spina bifida in offspring is investigated. To get detailed exposure information about the time period around conception, job, and task specific personal interviews were performed.

\section{Subjects and methods}

Hospital records of six academic hospitals, one regional hospital, and two rehabilitation centres in the Netherlands were searched to identify the cases and part of the controls. This resulted in 470 live born children with spina bifida aperta, born between 1 January 1980 and 31 December 1992, and 456 control children who were born healthy in the same period but who had experienced a cerebral trauma or meningitis during childhood. Most of the control group were 1894 children from the general population, born between 1 January 1980 and 31 December 1992, who were recruited from birth registries of 45 municipalities in the Netherlands. Stratified random sampling was performed to match the population based controls to the cases based on size of the municipality (in four categories) and geographical location.

Data collection was carried out in two steps (figure). In the first step, a postal questionnaire was sent to the total study population to collect information on occupation of the mother and on potentially confounding factors. From 80 mothers (21 cases and 59 controls) current addresses could not be obtained. Three hundred and forty nine case mothers $(78 \%)$ and 1604 control mothers (70\%) returned the questionnaire. In the second step, detailed information on occupational exposures was collected from a subset of the mothers by means of personal interviews at home. Respondents who indicated in the questionnaire that they were willing to participate in a personal interview $(78 \%$ and $71 \%$, respectively) were eligible for this part of the study. All of the eligible case mothers were enrolled, together with a random sample of $27.5 \%$ of the control mothers. This resulted in a study population of 274 cases and 314 controls.

As detailed interviews would be redundant for mothers who did not have a job or who worked in jobs without hazardous exposure, only mothers who worked in occupations with a potential for exposure to chemicals or radiation were actually interviewed (55 cases and 66 controls). This group included health care workers, cleaners, hairdressers, workers in industry and transport, and agricultural workers. The chemical exposure of the remaining women (housewives, household personnel, shop attendants, teachers, artistes, social workers, and clerical and managerial staff) was assumed to be negligible.

Because of an increased risk found for agricultural women, ${ }^{19}$ additional interviews were performed at a later date, with two case mothers and six control mothers working in agriculture. Originally, these women were not available for study (cases) or were not included in the control sample. Their information was only used for the agriculture specific descriptive analyses.

Ten different questionnaires were specifically designed for each of the following occupations: nurses, laboratory assistants, dental assistants, pharmaceutical assistants, physiotherapists, hairdressers, cleaners, printers, agricultural workers, and "occupations in industry or transport". In each interview, traditional work history questions on job title, industry, company name, number of hours worked, and tasks performed, were asked first.
Diagram of population in two study phases.

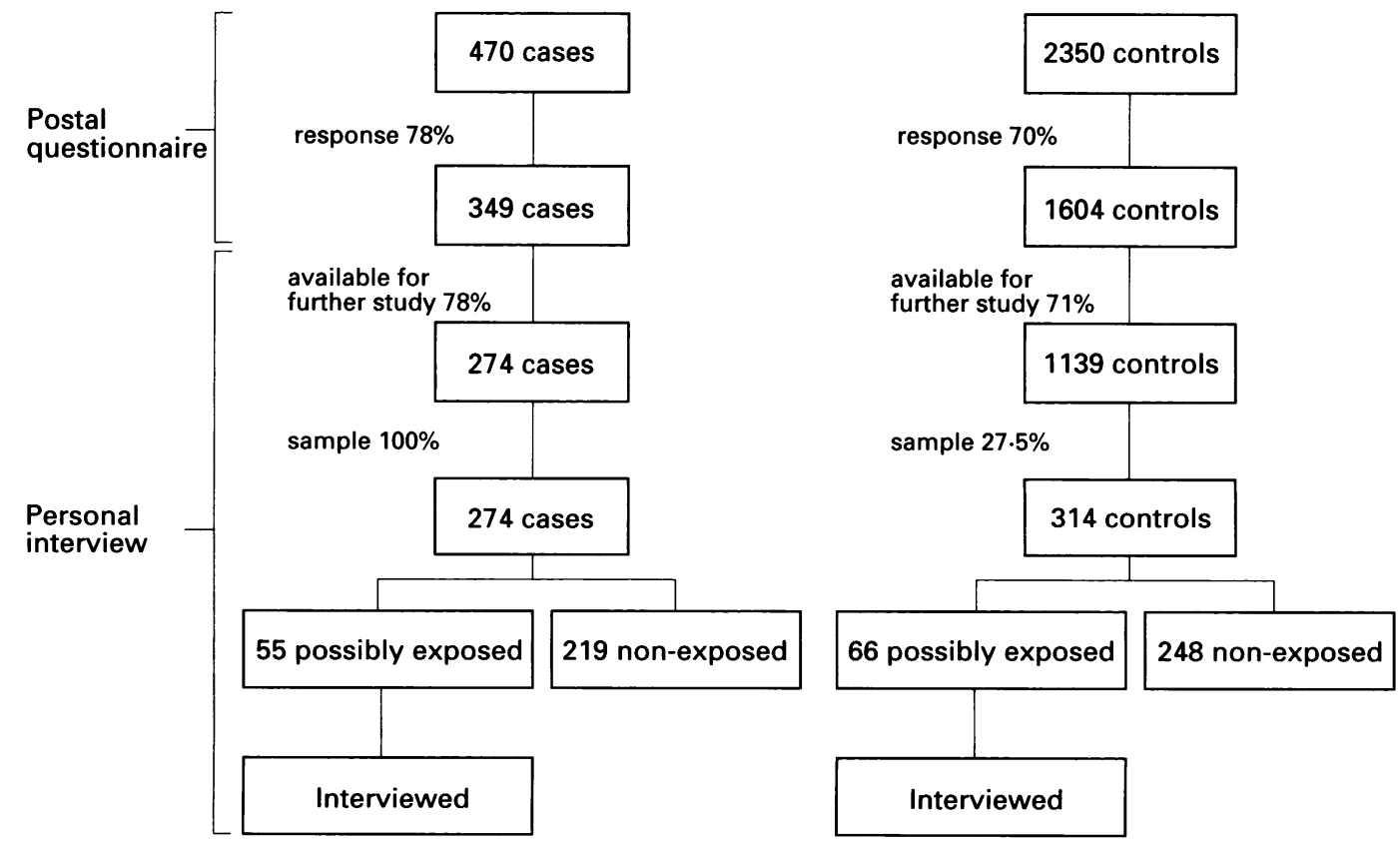


Table 1 Maternal occupation and risk of spina bifida aperta

\begin{tabular}{lccccc}
\hline Occupation & $\begin{array}{l}\text { Cases } \\
(n=349)\end{array}$ & $\begin{array}{l}\text { Controls } \\
(n=1604)\end{array}$ & $\begin{array}{l}\text { Crude } \\
\text { OR }\end{array}$ & $\begin{array}{l}\text { Adjusted } \\
\text { OR }\end{array}$ & $(95 \% C I)$ \\
\hline Nurses & 12 & 76 & $0 \cdot 8$ & $0 \cdot 8$ & $(0 \cdot 4-1 \cdot 5)$ \\
Nurse aids & 16 & 68 & $1 \cdot 1$ & $1 \cdot 2$ & $(0 \cdot 7-2 \cdot 1)$ \\
Other health care workers & 12 & 70 & $0 \cdot 8$ & $0 \cdot 8$ & $(0 \cdot 4-1 \cdot 6)$ \\
Cleaners & 13 & 32 & $1 \cdot 9$ & $1 \cdot 7$ & $(0 \cdot 9-3 \cdot 4)$ \\
Hairdressers & 3 & 17 & $0 \cdot 8$ & $0 \cdot 6$ & $(0 \cdot 2-2 \cdot 8)$ \\
Industry and transport & 15 & 56 & $1 \cdot 3$ & $1 \cdot 4$ & $(0 \cdot 8-2 \cdot 6)$ \\
Agricultural workers & 10 & 10 & $4 \cdot 8$ & $3 \cdot 4$ & $(1 \cdot 3-9 \cdot 0)$ \\
Non-exposed mothers & 268 & 1275 & & & \\
\hline
\end{tabular}

*Adjusted for a positive family history of neural tube defects of the father and use of ovulation stimulating agents by logistic regression; restricted for maternal use of vitamin A, antiepileptics, diabetes, diagnosis of homocysteinaemia, and consanguinity.

Subsequently, questions that were developed by the investigators on the basis of occupational hygiene information were used to inquire about every occupational task that had possibly been performed and on the associated use of chemicals and radiation, the frequency of the activity or exposure, the use of protective devices, and on exposure through the proximity of colleagues. For example, hairdressers were asked whether they applied hair sprays, what type of hair spray they used (with propellant gas or pump sprays), how often they applied hair dyes, and whether they had to prepare hair dyes themselves. Workers in the printing industry were asked, for example, what type of ink was used in the machines and whether they had to refill the ink supply and wash the ink rollers. At the end of each interview, a checklist with 17 categories of exposure was shown, to identify any agents that might have been missed. Detailed questions were asked again for the agents that were reported. The period of interest ranged from two weeks before conception until six weeks after conception, calculated from the duration of pregnancy that was reported in the questionnaire.

The exposures were classified into 23 categories (table 3). Some related exposures were grouped into larger categories (disinfecting agents, organic solvents, and hydrocarbons). The self reported interview information was used for coding of exposure into three different variables for each category: exposure yes or no, frequency of exposure, and kind of protective equipment used. Based on these variables, the level of exposure was assessed by the professional investigators with a four point scale (no

Table 2 Distribution of main background variables of cases and controls

\begin{tabular}{|c|c|c|}
\hline & $\begin{array}{l}\text { Cases } \\
(n=274) \\
n(\%)\end{array}$ & $\begin{array}{l}\text { Controls } \\
(n=314) \\
n(\%)\end{array}$ \\
\hline \multicolumn{3}{|l|}{ Education: } \\
\hline Low & $91(33 \cdot 7)$ & $85(27 \cdot 2)$ \\
\hline Moderate & $127(47 \cdot 0)$ & $158(50 \cdot 5)$ \\
\hline High & $52(19 \cdot 3)$ & $70(22 \cdot 4)$ \\
\hline Alcohol use (at least 1 glass/week) & $141(51 \cdot 6)$ & $174(55.4)$ \\
\hline Smoking (at least 1 cigarette/day) & $110(40 \cdot 6)$ & $130(41 \cdot 5)$ \\
\hline Maternal family history of NTD & $14(5 \cdot 1)$ & $4(1 \cdot 3)$ \\
\hline Paternal family history of NTD & $14(5 \cdot 1)$ & $3(1 \cdot 0)$ \\
\hline Primiparity & $124(45 \cdot 4)$ & $130(41 \cdot 4)$ \\
\hline Maternal age at childbirth (mean) & $28 \cdot 3$ & $28 \cdot 4$ \\
\hline Use of oral contraceptive & $99(36.5)$ & $104(33 \cdot 1)$ \\
\hline Use of ovulation stimulating agents & $12(4 \cdot 4)$ & $9(2 \cdot 9)$ \\
\hline Fetal loss (ever) & $63(23 \cdot 5)$ & $78(25 \cdot 6)$ \\
\hline
\end{tabular}

Family history of NTD = neural tube defect in sibling or in exposure, lightly, moderately, heavily exposed).

Descriptive analyses were performed within each of the selected occupational categories with potential exposure to identify differences between cases and controls in the number of exposed women and the frequency and level of exposure. Also, all mothers with and without potential for occupational exposure were combined to look at the possible effects of exposure to a particular agent, irrespective of occupation. Crude odds ratios (ORs) and adjusted ORs with $95 \%$ confidence intervals ( $95 \%$ CIs) were calculated by means of logistic regression for those agents to which at least 10 women were exposed. In the final analyses, the variables for level of exposure were dichotomised into no exposure $v$ any level of exposure and used as the primary exposure variables.

\section{Results}

The first phase of the study was meant to identify occupations with increased risks of spina bifida (table 1). After adjustment for confounders, an increased $\mathrm{OR}$ of $3.4(95 \% \mathrm{CI}$ 1.3-9.0) was found for women in agricultural occupations. An increased risk of 1.7 was found for cleaning women. More details about this part of the study have been described elsewhere. ${ }^{19}$

In the second phase, detailed information was gathered on occupational exposures from 55 case mothers and 66 control mothers who had an occupation with potential for chemical exposure. This group included 71 mothers working in health care, eight hairdressers, 15 mothers working in industry or in transport, 16 cleaners, and 11 mothers in agricultural occupations. Time between exposure and interview was not equally distributed between case and control mothers: $31.4 \%$ of the women reported exposures for the period $10-14$ years ago $(27 \cdot 3 \%$ of the cases and $34.8 \%$ of the controls), $35.5 \%$ for the period six to 10 years ago $(30.9 \%$ of the cases and $39.4 \%$ of the controls), and $33.1 \%$ for one to five years ago $(41 \cdot 8 \%$ of the cases and $25 \cdot 8 \%$ of the controls).

No substantial differences were found in the distribution of background variables between case mothers $(n=274)$ and control mothers $(n=314)$ in the total interview population in the second phase, except for a positive family history of neural tube defects for both mother and father (table 2).

Table 3 shows the number of exposed mothers within the different occupational groups, itemised for cases and controls, and the total number of case and control mothers with any level of exposure. It can be seen that, even within the occupational groups with a theoretically high potential for exposure, only a few women were exposed to hazardous agents such as antineoplastic drugs, ionising radiation, organic solvents, and pesticides. There was no frequent use of aggressive cleaning agents by the cleaning women and no differences could be detected between cases and controls. 
Table 3 Number of women exposed to chemical and physical agents by occupational category, and for all occupations combined

\begin{tabular}{|c|c|c|c|c|c|c|c|c|c|c|c|c|}
\hline & $\begin{array}{l}\text { Health } \\
\text { Cases } \\
29\end{array}$ & $\begin{array}{l}\text { are } \\
\text { Controls } \\
42\end{array}$ & $\begin{array}{l}\text { Hairdr } \\
\text { Cases } \\
3\end{array}$ & $\begin{array}{l}\text { ers } \\
5\end{array}$ & $\begin{array}{l}\text { Indust } \\
\text { Cases } \\
9\end{array}$ & $\begin{array}{l}y_{6}^{*} \text { Controls } \\
6\end{array}$ & $\begin{array}{l}\text { Cleaners } \\
\text { Cases } \\
7\end{array}$ & $\begin{array}{l}\text { Controls } \\
9\end{array}$ & $\begin{array}{l}\text { Agricu } \\
\text { Cases } \\
7\end{array}$ & $\begin{array}{l}\text { Controls } \\
4\end{array}$ & $\begin{array}{l}\text { All con } \\
\text { Cases } \\
274\end{array}$ & $\begin{array}{l}\text { bined } \\
\text { Controls } \\
314\end{array}$ \\
\hline Antibiotics & 11 & 12 & & & & & & & & & 11 & 12 \\
\hline Antineoplastic drugs & 4 & 6 & & & & & & & & & 4 & 6 \\
\hline Anaesthetics & 2 & 2 & & & & & & & & & 2 & 2 \\
\hline All disinfecting agents $†$ & 18 & 23 & & & & & 3 & 4 & 3 & 2 & 24 & 29 \\
\hline Sterilising agents $\ddagger$ & 3 & 0 & & & & & & & & & 3 & 0 \\
\hline Disinfectants $\ddagger$ & 14 & 15 & & & & & 0 & 1 & 3 & 0 & 17 & 16 \\
\hline All organic solvents & 21 & 26 & 3 & 5 & 5 & 2 & 0 & 1 & 0 & 2 & 29 & 35 \\
\hline Alcohol & 21 & 25 & & & 0 & 1 & & & & & 21 & 26 \\
\hline Other organic solvents & 2 & 3 & 2 & 0 & 5 & 2 & & & 0 & 2 & 9 & 7 \\
\hline Hair sprays & & & 3 & 4 & & & & & & & 3 & 4 \\
\hline Bleaching agents & & & 3 & 4 & & & & & & & 3 & 4 \\
\hline Permanent wave agents & & & 2 & 4 & & & & & & & 2 & 4 \\
\hline Hair dyes & & & 2 & 4 & & & & & & & 2 & 4 \\
\hline Pigments & 1 & 3 & & & 1 & 0 & & & & & 2 & 3 \\
\hline Mercury & 2 & 11 & & & & & & & & & 2 & 11 \\
\hline All hydrocarbons\| & & & & & 0 & 3 & 3 & 3 & 3 & 1 & 6 & 7 \\
\hline Fuels and exhaust fumes & & & & & 0 & 2 & 1 & 0 & 2 & 1 & 3 & 3 \\
\hline Pesticides & & & & & & & & & 2 & 2 & 2 & 2 \\
\hline Biological agents & 3 & 6 & & & & & & & 0 & 1 & 3 & 7 \\
\hline Biological active dust & 0 & 1 & & & & & & & 5 & 3 & 5 & 4 \\
\hline Dust & 0 & 1 & & & 8 & 1 & 6 & 9 & & & 14 & 11 \\
\hline Ionising radiation & 0 & 2 & & & & & & & & & 0 & 2 \\
\hline Non-ionising radiation & 3 & 4 & & • & 1 & 0 & & & & & 4 & 4 \\
\hline
\end{tabular}

*Including four women in the printing industry and two women in transport.

tComprising sterilising agents, disinfecting agents, and aggressive cleaning agents.

$\neq$ Including formaldehyde.

Comprising alcohol, other organic solvents, and hair sprays.

IIncluding mainly paint, glue, ink, xylene, ether.

||Comprising hydrocarbons, fuels, and exhaust fumes.

$\star \star$ Including mainly oil, turpentine, thinner, tar, and gasoline.

Table 4 Total number of agricultural women exposed to chemical agents*

\begin{tabular}{|c|c|c|}
\hline & $\begin{array}{l}\text { Cases } \\
9\end{array}$ & $\begin{array}{l}\text { Controls } \\
10\end{array}$ \\
\hline All disinfecting agentst & 4 & 3 \\
\hline Disinfectantsł & 4 & 1 \\
\hline Aggressive cleaning agents & 0 & 3 \\
\hline Other organic solventss & 0 & 2 \\
\hline All hydrocarbons? & 3 & 2 \\
\hline Hydrocarbons $\|$ & 1 & 2 \\
\hline Fuels and exhaust fumes & 3 & 2 \\
\hline Pesticides & 4 & 5 \\
\hline Biological agents & 0 & 3 \\
\hline Biological active dust & 6 & 6 \\
\hline
\end{tabular}

^ 11 agricultural women from table 3 plus eight with whom additional interviews were performed.

tComprising sterilising agents, disinfectants, and aggressive cleaning agents.

†Including formaldehyde.

Including mainly paint, glue, ink, xylene, ether.

TComprising hydrocarbons, fuels, and exhaust fumes.

||Including mainly oil, turpentine, thinner, tar, and gasoline.

Table 5 Frequency of exposure*: number of hours a week exposed to chemical and physical agents, for cases and controls.

\begin{tabular}{|c|c|c|c|c|c|c|c|c|}
\hline & \multicolumn{4}{|c|}{ Casest } & \multicolumn{4}{|c|}{ Controlst } \\
\hline & $n$ & $\begin{array}{l}\leqslant 1 \\
\text { h/week }\end{array}$ & $2-10$ & $>10$ & $n$ & $\begin{array}{l}\leqslant 1 \\
\text { h/week }\end{array}$ & $2-10$ & $>10$ \\
\hline Antibiotics & 11 & 5 & 5 & 1 & 12 & 6 & 6 & - \\
\hline Hormones & 4 & 1 & 2 & 1 & 10 & 6 & 4 & - \\
\hline Antineoplastic drugs & 4 & 3 & - & - & 6 & 6 & - & - \\
\hline Disinfectants $\ddagger$ & 17 & 9 & 8 & - & 16 & 10 & 6 & - \\
\hline Aggressive cleaning agents & 14 & 8 & 3 & 1 & 17 & 8 & 9 & - \\
\hline Alcohol & 21 & 6 & 15 & - & 26 & 14 & 11 & 1 \\
\hline Other organic solvents $\int$ & 9 & 3 & 3 & 1 & 7 & 3 & 2 & 2 \\
\hline Hair sprays & 3 & - & 3 & - & 4 & - & 4 & - \\
\hline Hydrocarbons & 4 & 1 & 2 & 1 & 5 & 2 & 1 & 2 \\
\hline Fuels and exhaust fumes & 3 & - & 2 & 1 & 3 & - & 1 & 2 \\
\hline Pesticides & 2 & - & 2 & - & 2 & 1 & 1 & - \\
\hline Biological agents & 3 & - & 1 & 2 & 7 & - & 3 & 3 \\
\hline Dust & 14 & - & 8 & 6 & 11 & - & 6 & 2 \\
\hline
\end{tabular}

*Combined categories (table 3), categories for which no detailed exposure information was available (mercury) and categories to which less than 10 women were exposed were not included (except for exposure to hair sprays, hydrocarbons, and pesticides).

tSome information on frequency of exposure is missing.

Including formaldehyde.

Including mainly paint, glue, ink, xylene, ether.

IIncluding mainly oil, turpentine, thinner, tar, and gasoline.
As well as the 11 women in agricultural occupations, additional interviews were performed with two case mothers and six control mothers (table 4). Four of the nine case mothers had been working in crop and stock farming, two mothers in poultry farming, one in market gardening, one in mushroom cultivation, and two in other agricultural occupations. Of the controls, six mothers had been working in crop and stock farming, one in fruit cultivation, two in plant and flower growing, and one in another agricultural occupation. Pesticide exposure does not seem to differ between case mothers (4/9) and control mothers $(5 / 10)$. The number of women exposed to biologically active dust is also similar.

Table 5 shows the frequency distributions of exposure. The intensity of exposure (given in number of hours a week) was low for case mothers as well as for control mothers in all exposure categories. Disinfectants, cleaning agents, and alcohol are the most widely used agents in this population. However, most of the women used these agents for only 10 hours or less a week, and $50 \%$ of reported use was for a maximum of one hour only. When all categories were combined, as little as $11 \%$ of the total number of chemicals and radiation used were handled more than 10 hours a week.

Table 6 shows the ORs and the $95 \%$ CIs that were calculated for the total group of potentially exposed and non-exposed occupations combined. The ORs were only calculated for chemical and physical agents to which at least 10 women were exposed. Controlling for potential confounders (use of vitamin $\mathrm{A}$, antiepileptics, ovulation stimulating agents, oral contraceptives, alcohol, smoking, positive family history of neural tube 
Table 6 Maternal occupational exposure ${ }^{\star}$ and risk of spina bifida aperta

\begin{tabular}{lccc}
\hline & $\begin{array}{c}\text { Casest } \\
(n=274)\end{array}$ & $\begin{array}{c}\text { Controlst } \\
(n=314)\end{array}$ & OR $(95 \% C I)$ \\
\hline Antibiotics & 11 & 12 & $1 \cdot 1(0 \cdot 5-2 \cdot 4)$ \\
Hormones & 4 & 10 & $0 \cdot 5(0 \cdot 1-1 \cdot 4)$ \\
Antineoplastic drugs & 4 & 6 & $0 \cdot 8(0 \cdot 2-2 \cdot 7)$ \\
All disinfecting agents & 24 & 29 & $0 \cdot 9(0 \cdot 5-1 \cdot 9)$ \\
$\quad$ Disinfectants & 17 & 16 & $1 \cdot 2(0 \cdot 6-2 \cdot 5)$ \\
$\quad$ Aggressive cleaning agents & 14 & 17 & $0 \cdot 9(0 \cdot 5-2 \cdot 0)$ \\
All organic solventsฐ & 29 & 35 & $0 \cdot 9(0 \cdot 6-1 \cdot 6)$ \\
$\quad$ Alcohol & 21 & 26 & $0 \cdot 9(0 \cdot 5-1 \cdot 7)$ \\
$\quad$ Other organic solvents & 9 & 7 & $1 \cdot 5(0 \cdot 6-4 \cdot 0)$ \\
Mercury & 2 & 11 & $0 \cdot 2(0 \cdot 1-0 \cdot 8)$ \\
All hydrocarbons\| & 6 & 7 & $1 \cdot 0(0 \cdot 3-3 \cdot 0)$ \\
Biological agents & 3 & 7 & $0 \cdot 5(0 \cdot 1-1 \cdot 9)$ \\
Dust & 14 & 11 & $1 \cdot 5(0 \cdot 7-3 \cdot 3)$ \\
\hline
\end{tabular}

^Only categories included to which at least 10 women were exposed.

tComprising sterilising agents, disinfectants, and aggressive cleaning agents.

tComprising sterilising ag

fComprising alcohol, other organic solvents, and hair sprays.

IIncluding mainly paint, glue, ink, xylene, ether

||Comprising hydrocarbons (including mainly oil, turpentine, thinner, tar, gasoline), fuels, and exhaust fumes.

defects, consanguinity, diabetes, diagnosis of homocysteinaemia, parity, and fetal loss) did not change the results. Therefore, the crude ORs are presented. Although some slightly increased ORs were found for organic solvents and dust (OR $=1.5), 95 \%$ CIs were wide. Some decreased ORs were found, of which the OR for exposure to mercury was significantly lower than one.

\section{Discussion}

It seemed that few women in this study were occupationally exposed to chemicals or radiation during early pregnancy. Furthermore, no differences were found between case and control mothers. Although a more than threefold increased risk in spina bifida was found for agricultural occupations, few mothers working in agriculture were exposed to pesticides or disinfectants. Nor could any differences in pesticide exposure be detected between case mothers and control mothers with agricultural occupations. Before interpreting these findings, however, some methodological issues must be considered.

For reasons of validity and efficiency, data collection was carried out in two steps. Firstly, information on occupational titles was collected from the total study population by means of postal questionnaires, in which also information on potentially confounding factors was gathered. This probably minimised misclassification on the confounders as questionnaire information on lifestyle factors may be less influenced by the tendency to give socially desirable answers than information gathered in a face to face situation. Furthermore, as the birth of the index child minus one year was used as a proxy for the period around conception in the postal questionnaires, more valid estimates of, for example, smoking and drinking habits are expected. Life style factors before conception probably better resemble life style habits in the first month of pregnancy, in which most women do not know that they are pregnant.

In the second phase, information on exposures was gathered from a sample of the potentially exposed mothers by means of personal interviews at home. Potentially exposed was defined as working in health care, industry, transport or agriculture, or working as a cleaner or hairdresser. Exposure of mothers working in non-exposed occupations such as clerical and managerial staff, teachers, artistes, and social workers, household personnel, shop attendants, and housewives was assumed to be negligible. Consequently, time consuming detailed exposure assessments were not performed for these mothers. This reduced the number of interviews and increased the efficiency of the study. Thus more attention could be paid to the quality of the remaining interviews and consequently to the validity of the exposure information. To achieve validity, occupation specific questionnaires were designed in which all the possible tasks performed were considered. For every specific task, questions were asked about frequency and duration of the task, the use of chemical or physical agents related to this task, use of protective devices, and exposure through use of chemicals by colleagues. By asking about exposure indirectly, by means of questions about specific tasks, and by asking direct questions on chemicals in the context of the occupation, recall is enhanced and validity of the study increased. ${ }^{15}$ As a consequence, information bias seemed less likely, although it can never be ruled out in a study with self reported data. Shaw and Gold described several studies specifically testing for information bias on exposures during pregnancy but have been unable to show its presence. ${ }^{20}$ Differential recall between cases and controls might have occurred as time between exposure and interview was unequally distributed in cases and controls. Forty two per cent of the cases reported exposures for the most recent period (one to five years ago) compared with $26 \%$ of the controls, thus recall might be slightly better for cases. Whether inaccurate recall of earlier periods causes a bias by under or overreporting, cannot be inferred.

A disadvantage of this two step data collection is that non-response accumulates. The response rates for the postal questionnaires were $78 \%$ for case mothers and $70 \%$ for control mothers. In the postal questionnaire the mothers were asked whether they were willing to participate in a personal interview later. Seventy eight per cent of the case mothers and $71 \%$ of the control mothers answered positively to this question. Differences in nonresponse between occupations could have resulted in selection bias. Also, the occupational distribution in the sampled control population may differ from the distribution in the total control population due to random sampling error. Comparison of the total postal questionnaire population (cases $=349$, controls $=1604$ ) with the interview study population $($ cases $=274$, controls $=314$ ), yielded similar occupational distributions in general, with the exception of cleaners and agricultural occupations. As a result of both mechanisms, the proportion of cleaners decreased by $37 \%$ among the cases and increased by $45 \%$ among the controls. For the agricultural occupations, the proportion among the cases did not 
change whereas the proportion among the controls increased by $116 \%$.

This might partly be caused by an over representation of hospital based controls who seemed to contain a higher proportion of agricultural workers (manuscript in preparation). As a consequence, an excess of agricultural controls and cleaners was found in the interviewed study population, which may have resulted in underestimation of the ORs for substances that were frequently being used by farmers and cleaners. Therefore, the frequencies of exposure have been considered within the specific occupational groups as well as in the combined population (table 3 ).

As a selection (only live born cases) of spina bifida cases were studied, the low exposure levels in this study might be a result of the so called "inverse dose-response relationship": a very high exposure could result in early fetal loss, whereas a lower one might result in a congenital malformation recognised at birth. ${ }^{21}$ Furthermore, misclassification on the outcome variable may have occurred. As open neural tube defects probably differ from closed neural tube defects in pathogenesis and aetiology, ${ }^{22}$ and these different forms cannot always be clinically distinguished, the case group may have been diluted with a few closed lesions. This may have led to a bias towards the null value.

Although the original size of the study was rather large, only a small proportion of women were exposed to chemicals during work and consequently, small numbers are involved in the analyses. Studies with small sample size or a low prevalence of exposure usually have a low statistical power. In this study, ORs were only calculated for chemical exposure categories that were reported at least 10 times among cases and controls. This constituted half of the categories. Power calculations for these categories yielded a power to detect an OR of 2 ranging from only $20 \%$ for antineoplastic drugs to $82 \%$ for all disinfecting agents. For the other exposure categories, including pesticides, sterilising agents and ionising radiation, the power was even lower and the data did not allow a proper study of these exposures. Instead, we had to resort predominantly to descriptive analyses. The low prevalence of exposure suggests that in the Netherlands, working conditions with exposure to chemicals during pregnancy are not unfavourable for most women. Also, the kind of exposures and their dose and intensity may not be so hazardous as to induce spina bifida in the fetus. As working conditions in other countries may be less favourable, the results from this study cannot be generalised to any given country.

In the scientific literature, some studies on neural tube defects and parental occupation have found a positive association between maternal agricultural occupations and spina bifida. ${ }^{1314}$ Studies on maternal occupational exposure, however, are scarce and inconclusive and do not show any evidence of a relation between maternal pesticide exposure and spina bifida. White et al found that environmental exposure to agricultural chemicals was associated with an increased number of children with spina bifida. ${ }^{23}$ However, exposure assessment was very crude. Brender and Suarez looked at occupational solvent and pesticide exposure, but did not find any exposure effect for the mothers because of low numbers of exposed cases and controls. ${ }^{18}$ Moreover, information on exposures was inferred from information on birth certificates and was not gathered by means of personal interviews. Recently, Nurminen $e t a l^{17}$ reported the results of a study on agricultural work and structural malformations. Three hundred and sixty five central nervous system defects were included, of which most were neural tube defects. The study was case-control by design and made use of interview data. A slightly increased risk was found when agricultural work was compared with non-agricultural work. Also, the authors especially focused on use of pesticides, but a potential effect could not be studied because of small numbers.

In conclusion, our results from the first phase of the study, in which job titles were considered, yielded an increased risk for women working in agricultural occupations. Without further study, this risk would easily be ascribed to pesticide use. However, in depth analyses of tasks and chemical exposure did not confirm this hypothesis, nor could any other occupational explanation be found for the increased risk of women working in agriculture. Remaining explanatory hypotheses besides chance are environmental pollution with pesticides on and around the farm, irrespective of a woman's own activities, and exposure to other factors that might not be work related, such as genetic, behavioural, or nutritional factors. Specific research among larger numbers of women in agricultural occupations, including both occupational and environmental factors might resolve the discrepancy found.

This study was supported by a grant from the Prinses Beatrix Fonds. We are most obliged to the Spina Bifida Teams of the University Hospital Groningen (Dr JH Begeer), the University Hospital of the Free University Amsterdam (Dr CA Kurk), the University Hospital Rotterdam (Dr PCJ de Laat), the rehabilitation centre the Maartensclinic (Dr MJ Poelma), the Elisabeth Hospital Tilburg (Dr JA Rammeloo), the rehabilitation centre Het Roessingh (Dr M Stroo), the Academic Medical Centre Amsterdam (Dr JW Weber), the University Hospital Utrecht (Dr $\mathrm{H}$ van Wieringen), and the University Hospital of Nijmegen (Dr RA Mullaart). We want to thank Ellen Arends, Miep (Dos Pelle interviews. Furthermore, we specially thank all the parents for their participation in the study.

1 Nevin NC, Johnston WP, Merrit JD. Influence of social class on the risk of recurrence of anencephalus and spina bifida. Dev Med Child Neurol 1981;23:155-9.

2 Elwood JM, Elwood JH. Epidemiology of anencephalus and spina bifida. Oxford: Oxford University Press, 1980.

3 Little J, Elwood JH. Socio-economic status and occupation. In: Elwood JM, Little J, Elwood JH, eds. Epidemiology and control of neural tube defects. Monographs in Epidemiology and control of neural tube defects. Monographs in epidemiology and biostatistics. V

4 Slattery ML, Janerich DT. The epidemiology of neural tube defects: a review of dietary intake and related factors tube defects: a review of dietary intake and related fact

5 Smithells RW, Seller MJ, Harris R, Fielding DW, Schorah CJ, Nevin NC, et al. Further experience of vitamin CJ, Nevin NC, et al. Further experience of vitamin

6 Wald N, Sneddon J, Frost C, Stone R. Prevention of neural tube defects: results of the Medical Research Council vitamin study. Lancet 1991;338:131-7.

7 Czeizel AE, Dudas I. Prevention of the first occurrence of neural tube defects by periconceptional vitamin supplementation. N Engl f Med 1992;327:1832-5.

8 Blatter BM, van der Star M, Roeleveld N. Review of neural 
tube defects. Risk factors in parental occupation and the environment. Environ Health Perspect 1994;102:140-5.

9 Hemminki K, Mutanen P, Luoma K, Salonieni I. Congenital malformations by the parental occupation in Finland. Int Arch Occup Environ Health 1980;46: 93-8.

10 Hemminki K, Mutanen P, Salonieni I, Luoma K Fingenital malformations and maternal occupation in Finland: multivariate

11 Sikorski R, Juszkiewicz T, Paszkowski T, SzprengierJuszkiewicz $\mathrm{T}$. Women in dental surgeries: reproductive hazards in occupational exposure to metallic mercury. Int Arch Occup Environ Health 1987;59:551-7.

12 Matte TD, Mulinare J, Erickson JD. Case-control study of congenital defects and parental employment in health care. Am 7 Ind Med 1993;24:11-23.

13 Hammond FG, Canache MF. Some epidemiological aspects of neural tube defects in Barquisimeto, Venezuela aspects of neural tube defects in Barquisimeto, Ven

14 Ericson A, Källén B, Löfkvist E. Environmental factors in the etiology of neural tube defects: a negative study. Environ Res 1988;45:38-47.

15 Stewart WF, Stewart PA. Occupational case-control studies: I. Collecting information on work histories and work-related exposures. Am f Ind Med 1994;26:
297-312.

16 Holmberg PC, Nurminen M. Congenital defects of the central nervous system and occupational factors during pregnancy A se-refent study. $\mathrm{Am} 7$ Ind $\mathrm{Med}$ 1980;1:167-76.

17 Nurminen T, Rantala K, Kurppa K, Holmberg PC. Agricultural work during pregnancy and selected strucAgricultural work during pregnancy and selected structural 30 .

18 Brender CJ, Suarez L. Paternal occupation and anencephaly. Am ₹ Epidemiol 1990;131:517-21.

19 Blatter BM, Roeleveld N, Zielhuis GA, Mullaart RA Gabreëls FJM. Spina bifida and parental occupation. Epidemiology (in press).

20 Shaw GM, Gold EB. Methodological considerations in the study of parental occupational exposures and congenital malformations in offspring. Scand $\mathcal{F}$ Work Environ Health 1988; 14:344-55.

21 Selevan SG, Lemasters GK. The dose-response fallacy in human reproductive studies of toxic exposures. $f$ Occup human reproductive

22 Lemire RJ. Neural tube defects. $¥ A M A$ 1988;259:558-62.

23 White FMM, Cohen FG, Sherman G, McCurdy R. Chemicals, birth defects and stillbirths in New Brunswick: associations with agricultural activity. Can Med Assoc $\mathcal{F}$ 1988;138:117-24.

\section{Instructions to authors}

Three copies of all submissions should be sent to: The Editor, Occupational and Environmental Medicine, BMJ Publishing Group, BMA House, Tavistock Square, London WC1H 9JR, UK. All authors should sign the covering letter as evidence of consent to publication. Papers reporting results of studies on human subjects must be accompanied by a statement that the subjects gave written, informed consent and by evidence of approval from the appropriate ethics committee. These papers should conform to the principles outlined in the Declaration of Helsinki (BMF 1964; ii:177).
If requested, authors shall produce the data on which the manuscript is based, for examination by the Editor.

Authors are asked to submit with their manuscript the names and addresses of three people who they consider would be suitable independent reviewers. They will not necessarily be approached to review the paper.

Papers should include a structured abstract of not more than 300 words, under headings of Objectives, Methods, Results, and Conclusions. Please include up to three keywords or key terms to assist with indexing. 